\title{
Thoracoscopic maneuvers for chest wall resection and reconstruction
}

\author{
Todd L. Demmy, MD, Sai Yendamuri, MBBS, Mark W. Hennon, MD, Elisabeth U. Dexter, MD, \\ Anthony L. Picone, MD, PhD, and Chukwumere Nwogu, MD
}

\begin{abstract}
Objective: The aim of this report is to describe technical maneuvers used to complete minimally invasive resections of the chest wall successfully.
\end{abstract}

\begin{abstract}
Methods: Case videos of advanced thoracoscopic chest wall resections performed at a comprehensive cancer center were reviewed, as were published reports. These were analyzed for similarities and also categorized to summarize alternative approaches.

Results: Limited chest wall resections en bloc with lobectomy can be accomplished with port placement similar to that used for typical thoracoscopic anatomic resections, particularly when the utility incision is close to the region of excision. Generally, chest wall resection precedes lobectomy. Ribs can be transected with Gigli saws, endoscopic shears, or high-speed drills. Division of bone and overlying soft tissue can be planned precisely using thoracoscopic guidance. Isolated primary chest wall masses may require different port position and selective reconstruction using synthetic materials. Patch anchoring can be accomplished by devices that facilitate laparoscopic port site fascial closure.
\end{abstract}

Conclusions: Thoracoscopic chest wall resections have been accomplished safely using tools and maneuvers summarized here. Further outcomes research is necessary to identify the benefits of thoracoscopic chest wall resection over an open approach. (J Thorac Cardiovasc Surg 2012;144:S52-7)

Thoracoscopic approaches are preferred for common thoracic procedures including pulmonary lobectomy because of their consistent salutary effect on outcomes likely brought about by reductions in perioperative pain. As experience has grown, so has reliability. Low conversion rates are now commonplace despite the challenges of higher stage tumors and the tissue effects brought on by induction chemoradiotherapy.

Whether thoracoscopic approaches benefit those needing more radical operations is both unclear and beyond the scope of this essay. However, circumstances ranging from a favorable anatomic tumor location to patient comorbidities that increase traditional thoracotomy risk prompt surgeons to consider alternative approaches. Evolving technology and surgical techniques now enable surgeons to incrementally extend their experience to accomplish more extensive resections ostensibly replicating their open operations. Inasmuch as large single-center series are not yet available to promulgate refined techniques on this subject, this report aims to summarize and categorize existing techniques reported for thoracoscopic chest wall

From the Department of Thoracic Surgery, Roswell Park Cancer Institute, Buffalo, NY.

Disclosures: Authors have nothing to disclose with regard to commercial support.

Presented at the 3rd International Minimally Invasive Thoracic Surgery Summit, Boston, Massachusetts, October 7-8, 2011.

Received for publication Oct 31, 2011; revisions received March 31, 2012; accepted for publication June 5, 2012; available ahead of print June 28, 2012.

Address for reprints: Todd L. Demmy, MD, Department of Thoracic Surgery, Roswell

Park Cancer Institute, Elm and Carlton St, Buffalo, NY 14263 (E-mail: todd.

demmy@ roswellpark.org).

$0022-5223 / \$ 36.00$

Copyright (c) 2012 by The American Association for Thoracic Surgery

http://dx.doi.org/10.1016/j.jtcvs.2012.06.005 resection as a reference for those considering adoption of this approach.

\section{METHODS}

An institutional review board-approved library of deidentified, archived, unedited video of medium- to high-complexity thoracoscopic lung resections from 2004 to 2011 was compiled for systematic review for the purpose of documenting past and current thoracoscopic experience. Procedural innovations developed at our comprehensive cancer center, as well as other reported techniques to aid in the management of bone and other chest wall tissues, were categorized and tabulated.

In addition, PubMed was searched using the following search terms: "VATS" or "Thoracoscopic" or "Minimally Invasive", "rib" or "chest wall" or "T3" or "bone"; and "resection" or "excision" or "removal" or "reconstruction". This yielded 1395 abstracts that were winnowed to 68 articles that indicated that the thoracoscope was used to perform or enhance chest wall resection or intrathoracic bone manipulation. Select references are cited here. The papers were largely case reports or small case series except for operations performed for more common problems such

TABLE 1. General steps of chest wall resection

Score planned margins with cautery device.
Divide ribs close to utility incision with standard rib cutter
(Giertz rib shears).
Divide intercostal muscles with energy sealing device.
Place durable instrument to mobilize and retract rib block.
Dissect subcutaneous and muscular plane from specimen (extrathoracic
plane, thin long retractors to hold tissue away from ribs).
Divide intercostal tissues with energy device.
Divide ribs away from utility incision (endoscopic bone cutter,
high-speed burr).
Perform anatomic lung resection (if necessary).
Extract specimen.
Reconstruct chest wall (if necessary).


TABLE 2. Troubleshooting guide for confronting thoracic bone anatomy

Patient positioning

Exposure/camera port

Utility port selection (see text)

Working port

Dividing ribs/bone

Dividing chest wall tissues including intercostal bundles

Retracting rib block

\section{Retraction overlying or} nearby tissues

Extracting specimen

Rib/patch stabilization

Diaphragm control

Bleeding control
Lateral decubitus with same modifications for desired chest wall resection if accomplished open.

Tilting of table for extreme anterior or posterior resections. Possible use of pads to elevate portion of chest wall off table.

Flexible or $30^{\circ}$ camera to maximize view angles.

Alternate viewing through utility incision.

Alternate viewing through retraction working ports with 5-mm scopes.

Place near site of rib resection to facilitate extraction of rib block and suturing of prosthetic material (if required).

Consider anterior (wider intercostal space) for access to vital hilar structures if anatomic lung resection is required or to allow enough space for extraction of the rib block.

Place for optimal manipulation of chest wall block (typically opposite from side of invasion so that rib-cutting instruments may approach the bone perpendicularly).

Standard rib shears for bone near utility incision-excising a $1 \mathrm{~cm}$ section of rib increases exposure.

Endoscopic bone shears (Sofamor Danek) passed through the port with the most favorable angle (most perpendicular with rib). Since jaws are small, may need to flip shears to complete division from other rib edge.

High-speed drill burrs, eg, extended length 4-mm (Midas Rex, Black Max) generally through utility incision. Irrigate area while drilling and divide the near then deep table of bone. Probe with the drill off to determine what bone remains.

Gigli saw (passed through stab incision over rib-less desirable if multiple ribs are resected).

Extended length/endoscopic rongeurs (Kerrison, Urschel-Leksell) passed through the most accessible port.

Pass tools through the port or wound protector if close margin is suspected.

Score planned resection first with unipolar extended cautery through any convenient port.

Cutting energy devices (Ligasure, Enseal, ultrasonic shears).

Divide after ribs on one side are divided and block is more mobile.

Hook intercostal neurovascular bundle with right-angle clamp to deliver away from chest wall into jaws of energy device.

Use sturdy endoscopic instrument capable of bending rib block away from rest of chest wall. Examples: endoscopic fan retractor (closed), heavy-shafted lung grasper (let rib edge hook into oval opening on lung grasper), Diamond-Flex retractor.

Retract with fingers through utility port.

Use subxiphoid approach with or without hand assist. ${ }^{8}$

Use sternal lift technique to open subxiphoid space for extraction ${ }^{9}$

Use controlled rib osteotomy and repair to increase space for extraction. ${ }^{10-12}$

Thin retractor through utility port (eg, Wylie retractor).

Self-retaining (eg, Bookwalter) retractor through utility port.

Use of counterincisions on opposing edges of the rib block (that may be used later to anchor reconstruction prosthetics) to pass a sling such as a large Penrose drain for external retraction ${ }^{13}$

Use wound protector and/or sturdy nylon extraction sac.

Orient rib block perpendicular with exit point.

Deliver leading edges of rib through utility port manually before attempting to extract rest of specimen.

Consider use of alternative site, such as subxiphoid extraction.

Take care that bone fragments do not rupture extraction sac.

Measure patch based on extracted specimen (1 cm larger all sides).

Punch anchoring holes in desired patch material while extracorporeal.

Unfurl rolled patch internally and suture.

Alternatively, place deepest sutures, bring ends out through access incision and through patch, and then parachute patch into cavity.

Use needle suture passer (Carter-Thomason CloseSure System) to deliver anchoring sutures through 2-mm incisions. Tie sutures externally and allow knots to retract beneath skin or tie sutures internally with intracorporeal techniques.

Finish anchoring of patch directly through utility incision.

Provide additional rigidity by using titanium plating with screws or absorbable products (Bio-bridge).

Use suture to retract through lower port.

Use 5-mm retractor with self-retaining holder to depress diaphragm.

Unipolar or bipolar cold cautery (eg, Aquamantys) devices.

Energy devices (see intercostal division, above).

Topical fibrin glue or similar products. 


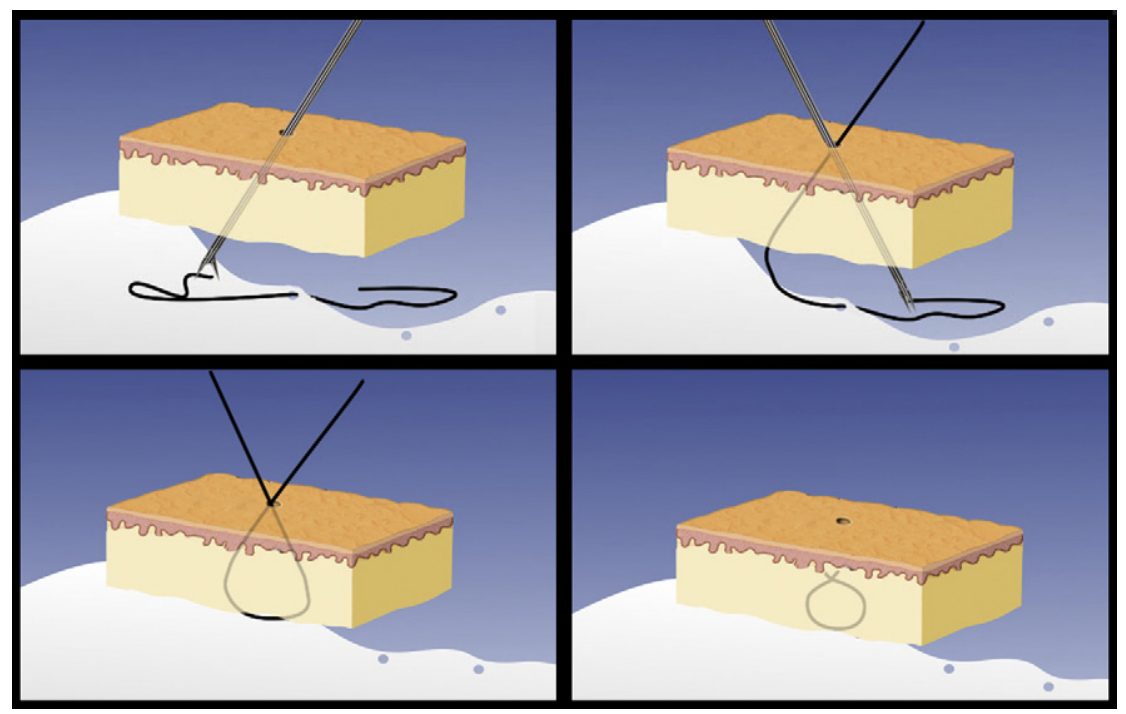

FIGURE 1. Sequence for placing the suture to anchor the patch to the chest wall. The last frame shows the knot retracted beneath the miniature stab incision. Alternatively, each end of the suture can be placed outside and then passed through the prosthesis to be tied internally (see Figure 2, B).

as scoliosis and pectus excavatum. None of the evidence was from a randomized comparison.

\section{RESULTS}

Technical maneuvers for complete thoracoscopic chest wall resection with or without reconstruction were abstracted from 10 procedures. Seven were performed concomitant with anatomic lung resection (all of which had induction therapy) and 3 had primary or metastatic isolated lesions. All were accomplished without conversions or major intraoperative complications. The general approach used to achieve technical success is outlined in Table 1.

During the course of this early experience, adaptations or introductions of technology often used in other specialties were used to overcome obstacles. These and those recommended by other investigators are presented in a troubleshooting guide form in Table 2. The position of the utility incision requires careful thought, especially if a concomitant procedure such as a formal lung resection is required. It may be best to avoid a wound over or near the rib block to improve healing or if that vantage point would make vascular division tedious. Generally, it is best to perform a thoracoscopic exploration through 1 or 2 ports before choosing the utility incision that provides the optimal compromise for all the intended steps of the procedure.

To anchor prosthetic material to the chest wall, we used a device that was designed to close full-thickness fascia to prevent laparoscopic port hernias (Carter-Thomason CloseSure System; CooperSurgical, Inc, Trumbull, Conn). Rather than closing a defect, the needle-like suture passing device can be passed twice through the same $2-\mathrm{mm}$ stab incision at $90^{\circ}$ angles to capture underlying fascia and rib. The knot can be tied intracorporeally or externally (Figure 1). Measuring the 2-mm polytetrafluoroethylene patch while extracorporeal and then prepunching its edges with a Cone skull punch eliminates the sometimes difficult task of trimming or needle puncturing such sturdy material with endoscopic instruments. The suture passing device can pass through these punch holes quite easily (Figure 2).
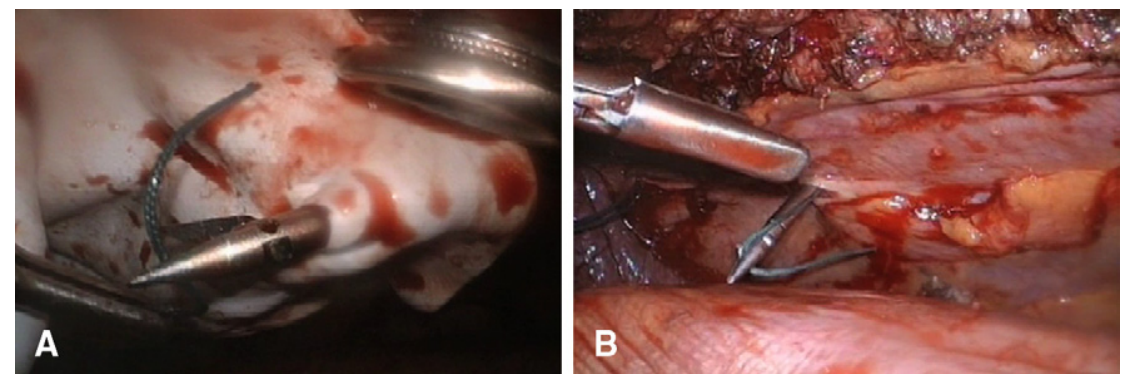

FIGURE 2. Operative photos. A, Passing the device within the prepunched polytetrafluoroethylene hole ready to retrieve the suture as is depicted in the upper frames of Figure 1. B, The alternative use, passing the suture ends first through the chest wall to be retrieved for placement through the prosthesis extracorporeally. 
TABLE 3. Selected reports of thoracoscopic bone manipulation and resection for various diseases

\begin{tabular}{|c|c|c|}
\hline Bone procedure & Pathology & $\begin{array}{c}\text { Aggregate case } \\
\text { number from } \\
\text { references* }\end{array}$ \\
\hline Corpectomy & Tumor, trauma & 44 \\
\hline Discectomy & Herniation & 25 \\
\hline En bloc resection & Lung cancer extension & 4 \\
\hline First rib resection & Thoracic outlet & 94 \\
\hline Rib resection & $\begin{array}{l}\text { Trauma, metastasis, Castleman } \\
\text { disease, fibrous dysplasia }\end{array}$ & 4 \\
\hline Spine foramen & Dumbbell nerve tumor & 3 \\
\hline $\begin{array}{l}\text { Sternal alignment } \\
\text { with or without rib } \\
\text { resection }\end{array}$ & Pectus excavatum/carinatum & 1591 \\
\hline Scapular resection & Osteochondroma & 1 \\
\hline $\begin{array}{l}\text { Multiple spine } \\
\text { resections }\end{array}$ & Scoliosis & 263 \\
\hline Spine fracture repair & Trauma & 583 \\
\hline Spine debridement & Infection, tumor & 28 \\
\hline
\end{tabular}

*See Appendix 1 for selected supporting citations.

\section{DISCUSSION}

There is a slowly growing set of technical maneuvers and tools to enable minimally invasive approaches to the chest wall for tumors and other pathologic conditions related to thoracic bone anatomy. Although the thoracic surgical literature has been slow to show interest in this topic, there are large series of thoracoscopic operations from other disciplines in which considerable bone ablation and manipulation have been accomplished successfully. We have observed that there may be faster recovery, although few reports have good comparison groups. There are pain physiology theories that could explain why pain would be less by approaches that "on the surface" are less invasive. ${ }^{1}$

Our review identified these procedures and they are listed in Table 3. Special bone-cutting tools have been developed by interested orthopedic and neurosurgeons, including minimally invasive devices, to procure bone grafts. ${ }^{2}$ Even flaps for coverage like the latissimus dorsi have been mobilized by videoendoscopy. ${ }^{3}$

The optimal patient on whom to adopt this approach is controversial. However, frail patients who will have difficulty with open thoracotomies are our preferred group for extending indications. In 1996, Mineo and associates ${ }^{4}$ used the same ideology and applied less-invasive laser resection for T3 chest wall tumors in 10 patients who had poor pulmonary function. What is more certain is that the thoracoscope is an excellent tool to plan rib resections in open cases to avoid excessive or inaccurate margins. ${ }^{5-7}$ For instance, methylene blue can be injected from the inside under thoracoscopic guidance into the desired edges of the chest wall margins. ${ }^{5}$ That way, precise rib osteotomies can be made, dividing chest wall tissues outside in. A summary of useful equipment compiled in this review is offered in Table 4.

Because the experience with thoracoscopic approaches for chest wall tumors is limited largely because of the infrequent nature of suitable cases, it will require some time and probably a cooperative group framework to determine whether such procedures offer an advantage. In the meantime, knowledge of the techniques described herein could prove useful for the surgeon experienced in video-assisted thoracic surgery who encounters a situation that lends itself to such an approach.

TABLE 4. Selected useful instruments and their manufacturers

\begin{tabular}{lll}
\hline \multicolumn{1}{c}{ Class } & \multicolumn{1}{c}{ Equipment } & \multicolumn{1}{c}{ Manufacturer } \\
\hline Bone drills & Midas Rex & Medtronic, Inc, Minneapolis, Minn \\
& Black Max & Anspach, Inc, Palm Beach Gardens, Fla \\
Bone saws & Gigli & Multiple \\
Endoscopic rib shears & Sofamor-Danek & Medtronic, Inc, Minneapolis, Minn \\
Energy sealing/division & Ligasure & Covidien, Inc, Mansfield, Mass \\
& Enseal & Ethicon, Inc, Somerville, NJ \\
Long rongeurs & Kerrison & Multiple \\
& Urschel-Leksell & Multiple \\
Low profile retractor & 5-mm Diamond-Flex & Cardinal Health, Dublin, Ohio \\
Open rib shears & Giertz & Multiple \\
Punch for chest wall polytetrafluoroethylene graft & Cone skull punch & Multiple \\
Rib stabilization & Absorbable Bio-Bridge & Acute Innovations, Hillsboro, Ore \\
Sturdy thoracoscopic retractors & Titanium maxillofacial systems & Multiple \\
& 10-mm Lung grasping forceps & Scanlon, Inc, Saint Paul, Minn \\
Suture passing & Lewis VATS Grasper & Thoramet Surgical, Inc, Irvington, NJ \\
Topical sealing cold cautery & Carter-Thomason CloseSure System & CooperSurgical, Inc, Trumbull, Conn \\
Utility port retraction & Aquamantys unipolar and bipolar & Salient Surgical Technologies, Inc, Portsmouth, NH \\
& Wylie & Multiple \\
\hline
\end{tabular}

VATS, Video-assisted thoracic surgery. 


\section{References}

1. Demmy TL, Nwogu CE, Yendamuri S. Thoracoscopic chest wall resection: what is its role? Ann Thorac Surg. 2010;89:S2142-5.

2. Steffen T, Downer P, Steiner B, Hehli M, Aebi M. Minimally invasive bone harvesting tools. Eur Spine J. 2000;9(Suppl 1):S114-8.

3. Martinez-Ferro M, Fraire C, Saldana L, Reussmann A, Dogliotti P. Complete videoendoscopic harvest and transposition of latissimus dorsi muscle for the treatment of Poland syndrome: a first report. J Laparoendosc Adv Surg Tech A. 2007; 17:108-13.

4. Mineo TC, Ambrogi V, Pompeo E, Nofroni I, Casciani CU. En bloc minimal laser resection for T3-chest wall lung cancer in patients with poor pulmonary function. Chest. 1996;110:1092-6.

5. Gera PK, La Hei E, Cummins G, Harvey J. Thoracoscopy in chest wall Ewing's sarcoma. J Laparoendosc Adv Surg Tech A. 2006;16:509-12.

6. Ninomiya H, Maeda M, Matsuzaki Y, Nakamura K, Sekiya R, Onitsuka T. Giant cell tumor of the rib. Jpn J Thorac Cardiovasc Surg. 2002;50:224-6.

7. Podbielski FJ, Issa RA, Fontaine JP, Rodriguez HE. Thoracoscopic transillumination in chest wall resection. Asian Cardiovasc Thorac Ann. 2004;12:171-2.
8. Long H, Zheng Y, Situ D, Ma G, Lin Z, Wang J. Hand-assisted thoracoscopic surgery for bilateral lung metastasectomy through sternocostal triangle access. Ann Thorac Surg. 2011;91:852-8.

9. Takeo S, Fukuyama S. Video-assisted thoracoscopic resection of a giant anterior mediastinal tumor (lipoma) using an original sternum-lifting technique. Jpn J Thorac Cardiovasc Surg. 2005;53:565-8.

10. Yamaguchi A, Hashimoto O, Tamaki S. French-window thoracotomy: postoperative pain avoidance for short-stay lung cancer surgery. Jpn J Thorac Cardiovasc Surg. 2006;54:520-7.

11. Shigemura N, Hsin MK, Yim AP. Segmental rib resection for difficult cases of video-assisted thoracic surgery. J Thorac Cardiovasc Surg. 2006;132: 701-2.

12. Raman J, Onsager D, Straus D. Rib osteotomy and fixation: enabling technique for better minithoracotomy exposure in cardiac and thoracic procedures. J Thorac Cardiovasc Surg. 2010;139:1083-5.

13. Rocco G, Fazioli F, Martucci N, Cicalese M, La Rocca A, La Manna C, et al. Video-assisted thoracic surgery rib resection and reconstruction with titanium plate. Ann Thorac Surg. 2011;92:744-5.

\section{APPENDIX 1.}

\section{Corpectomy}

1. Cappuccio M, Gasbarrini A, Donthineni R, Beisse R, Boriani S. Thoracoscopic assisted en bloc resection of a spine tumor. Eur Spine J. 2011;20(Suppl 2): S202-5.

2. Dickman CA, Rosenthal D, Karahalios DG, Paramore CG, Mican CA Apostolides PJ, et al. Thoracic vertebrectomy and reconstruction using a microsurgical thoracoscopic approach. Neurosurgery. 1996;38:279-93.

3. McAfee PC, Regan JR, Fedder IL, Mack MJ, Geis WP. Anterior thoracic corpectomy for spinal cord decompression performed endoscopically. Surg Laparosc Endosc. 1995;5:339-48.

4. Mori K, Imai S, Saruhashi Y, Matsusue Y. Thoracoscopic en bloc extirpation for subperiosteal osteoid osteoma of thoracic vertebral body: a rare variety and its therapeutic consideration. Spine J. 2011;11:e13-8.

5. Han PP, Kenny K, Dickman CA. Thoracoscopic approaches to the thoracic spine: experience with 241 surgical procedures. Neurosurgery. 2002;51(5 Suppl):S88-95.

6. van Dijk M, Cuesta MA, Wuisman PI. Thoracoscopically assisted total en bloc spondylectomy: two case reports. Surg Endosc. 2000;14:849-52.

\section{Discectomy}

1. Bisson EF, Jost GF, Apfelbaum RI, Schmidt MH. Thoracoscopic discectomy and instrumented fusion using a minimally invasive plate system: surgical technique and early clinical outcome. Neurosurg Focus. 2011;30:E15.

\section{En Bloc Resection}

1. Widmann MD, Caccavale RJ, Bocage JP, Lewis RJ. Video-assisted thoracic surgery resection of chest wall en bloc for lung carcinoma. Ann Thorac Surg. 2000;70:2138-40.

2. Yendamuri S, Nwogu CE, Demmy TL. Thoracoscopic lobectomy with chest wall resection after neoadjuvant therapy. Innovations (Phila). 2009;4:36-8.

\section{First Rib Resection}

1. Loscertales J, Congregado M, Jimenez MR. First rib resection using videothorascopy for the treatment of thoracic outlet syndrome. Arch Bronconeumol. 2011; 47:204-7.

2. Ohtsuka T, Wolf RK, Dunsker SB. Port-access first-rib resection. Surg Endosc. 1999;13:940-2.

3. Martinez BD, Wiegand CS, Evans P, Gerhardinger A, Mendez J. Computerassisted instrumentation during endoscopic transaxillary first rib resection for thoracic outlet syndrome: a safe alternate approach. Vascular. 2005;13: 327-35.

4. Morgan CJ, Lyons J, Ling BC, Maher PC, Bohinski RJ, Keller JT, et al. Video-assisted thoracoscopic dissection of the brachial plexus: cadaveric study and illustrative case. Neurosurgery. 2006;58(4 Suppl 2):ONS-287-90; discussion ONS-290-1.

\section{Rib Resection}

1. Kurai M, Kondo R, Kobayashi N, Hyogotani A, Yoshida K, Amano J. Castleman's disease arising from the chest wall. Jpn J Thorac Cardiovasc Surg. 2006;54:555-7.

2. Nakagiri T, Akashi A, Shigemura N. Thoracoscopic rib resection using a Gigli saw. Ann Thorac Surg. 2005;80:755-6.

3. Sing RF, Mostafa G, Matthews BD, Kercher KW, Heniford BT. Thoracoscopic resection of painful multiple rib fractures: case report. J Trauma. 2002;52:391-2.

\section{Spine Foramen}

1. Ghostine S, Vaynman S, Schoeb JS, Cambron H, King WA, Samudrala S, et al. Image-guided thoracoscopic resection of thoracic dumbbell nerve sheath tumors. Neurosurgery. 2012;70:461-7; discussion 468.

\section{Sternal Alignment With or Without Rib Resection}

1. Abramson H, D'Agostino J, Wuscovi S. A 5-year experience with a minimally invasive technique for pectus carinatum repair. J Pediatr Surg. 2009;44: 118-23.

2. Horch RE, Stoelben E, Carbon R, Sultan AA, Bach AD, Kneser U. Pectus excavatum breast and chest deformity: indications for aesthetic plastic surgery versus thoracic surgery in a multicenter experience. Aesthetic Plast Surg. 2006;30: 403-11.

3. Nuss D, Kelly RE Jr. Minimally invasive surgical correction of chest wall deformities in children (Nuss procedure). Adv Pediatr. 2008;55: 395-410.

4. Varela P, Torre M. Thoracoscopic cartilage resection with partial perichondrium preservation in unilateral pectus carinatum: preliminary results. J Pediatr Surg. 2011;46:263-6.

\section{Scapular Resection}

1. Perez D, Cano JR, Caballero J, Lopez L. Minimally-invasive resection of a scapular osteochondroma. Interact Cardiovasc Thorac Surg. 2011;13:468-70.

\section{Multiple Spine Resections}

1. Al Sayyad MJ, Crawford AH, Wolf RK. Video-assisted thoracoscopic surgery: the Cincinnati experience. Clin Orthop Relat Res. 2005;434: 61-70.

2. Karami M, Ilharreborde B, Morel E, Fitoussi F, Pennecot GF, Mazda K. Video-assisted thoracoscopic surgery (VATS) for the treatment of scolioticrib hump deformity. Eur Spine J. 2007;16:1373-7.

3. Krasna MJ, Jiao X, Eslami A, Rutter CM, Levine AM. Thoracoscopic approach for spine deformities. J Am Coll Surg. 2003;197:777-9.

4. Norton RP, Patel D, Kurd MF, Picetti GD, Vaccaro AR. The use of thoracoscopy in the management of adolescent idiopathic scoliosis. Spine (Phila Pa 1976). 2007; 32:2777-85. 
5. Rothenberg S, Erickson M, Eilert R, Fitzpatrick J, Chang F, Glancy G, et al. Thoracoscopic anterior spinal procedures in children. J Pediatr Surg. 1998;33: 1168-70.

6. Son-Hing JP, Blakemore LC, Poe-Kochert C, Thompson GH. Video-assisted thoracoscopic surgery in idiopathic scoliosis: evaluation of the learning curve. Spine (Phila Pa 1976). 2007;32:703-7.

\section{Spine Fracture Repair}

1. Kim DH, Jahng TA, Balabhadra RS, Potulski M, Beisse R. Thoracoscopic transdiaphragmatic approach to thoracolumbar junction fractures. Spine J. 2004;4: 317-28.
2. Khoo LT, Beisse R, Potulski M. Thoracoscopic-assisted treatment of thoracic and lumbar fractures: a series of 371 consecutive cases. Neurosurgery. 2002;51(5 Suppl):S104-17.

\section{Spine Debridement}

1. Jayaswal A, Upendra B, Ahmed A, Chowdhury B, Kumar A. Video-assisted thoracoscopic anterior surgery for tuberculous spondylitis. Clin Orthop Relat Res. 2007;460:100-7.

2. Kan P, Schmidt MH. Minimally invasive thoracoscopic approach for anterior decompression and stabilization of metastatic spine disease. Neurosurg Focus. 2008; 25:E8. 